Harris, L.M. et al. (2017). Water materialities and citizen engagement: Testing the implications of water access and quality for community engagement in

Ghana and South Africa.

Society andNatural Resources.

http://dx.doi.org/10.1080/08941920.2017.1364818

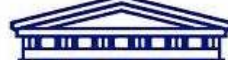

\title{
Water materialities and citizen engagement: Testing the implications of water access and quality for community engagement in Ghana and South Africa
}

\author{
Leila M. Harris, Danika Kleiber, Lucy Rodina, Sule Yaylaci, Jacqueline Goldin and
} Germaine Owen

\begin{abstract}
We analyze the relationship between perceptions of domestic water access, and quality, in relation community engagement. While others have suggested linkages between material conditions of water access and engagement (e.g., that poor water access might spur engagement), to date there have been no studies those test these relationships using statistical methods. Based on a quantitative analysis of survey data from underserved sites in Accra, Ghana, and Cape Town, South Africa, our results show that water access and quality are both predictive of community engagement. The analysis also makes a strong case that there are different dimensions when considering the material conditions of water-in this case, water access and quality each condition engagement in opposite directions. Furthermore, consistent with other studies, our study also shows different demographics (notably gender) mediate these relationships in important ways.
\end{abstract}

\section{Introduction: Community Engagement and Materialities of Water}

Recent conceptual debates have highlighted linkages between conditions of environmental resources and community engagement-from work in environmental citizenship (Latta and Wittman 2012), to "environmentality" (Agrawal 2005) or notions of "hydraulic citizenship" (Anand 2011). While several works have suggested that material conditions of resources influence and shape sociopolitical processes of engagement, governance, or citizenship, there is still limited understanding of these dynamics. To address this gap, we offer a statistical analysis of the relationship between water materialities and community engagement. Drawing on survey data from underserved urban areas of Accra, Ghana, and Cape Town, South Africa, the analysis considers two dimensions of water materialities: access and quality. Results suggest that water access and quality are significant predictors of community engagement, albeit in opposite directions (access has a negative relationship, and quality a positive one). As such, our study lends support to the broad interest in the ways that material resource conditions influence sociopolitical processes, while also underscoring the need for clarity regarding specific facets of materialities. Our results also validate arguments in the literature related to the variability of water-society linkages 
with respect to gender and country context.

\section{Resource Materialities: Debates from Political Ecology, Science and Technology Studies, and Allied Fields}

Literatures on materiality from political ecology, science and technology studies, and allied traditions have pointed to the biophysical and ecological characteristics or qualities of resources, suggesting that material and infrastructural conditions have important consequences for sociopolitical processes, including the ways in which resources are used, governed, or imagined (cf., Bakker 2003). For instance, Kaika (2005) discusses how infrastructures that enable easy access to water (by simply turning on a home tap) may contribute to a sense of disassociation between residents and the resources on which they depend. Several recent contributions in anthropological and geographical literatures have furthered the interest in infrastructural conditions as key to shifting subjectivities, altered state-society dynamics, or a suite of related sociopolitical processes (Kooy and Bakker 2008; Birkenholtz 2009; Amin 2014; Rodina and Harris 2016; Larkin 2013).

These contributions bolster the claim by Bakker and Bridge (2006) that a focus on "materialities" is a critical new direction for political ecology, resource geography, and environmental studies-allowing us to better theorize and account for physicality and the copresence of humans, nonhuman natures, and infrastructures (Sultana 2009; Barnes and Alatout 2012; Wutich et al. 2013). According to Anand (2011), hydrosocial approaches have revealed a great deal about power dynamics and uneven flows of water, yet little has been done to date on "how and why the materiality of water itself is crucial to ... political formations (p. 544)." Our treatment of water materialities and community engagement linkages offers a partial response to this gap.

Specifically, we test the potential connections between material water conditions and community engagement processes-a linkage that has been implied in the literature (see discussion of key hypotheses, below) but as yet has not been sufficiently explored. It is worth noting that the role of community engagement in contributing to better resource conditions and infrastructures is a clear theme in the literature, with the idea that stronger engagement often leads to improved conditions (e.g., extensive work on social capital, e.g., Putnam 1993; Pretty and Ward 2001; or contributions specific to water, e.g., Linton 2012; Sultana and Loftus 2012). Here, we consider the less investigated inverse possibility-that material conditions may be significant factors that affect community engagement.

\section{Material Conditions and Community Engagement}

Why might material water conditions be associated with patterns of community engagement? Amin's (2014) work in Brazil concludes that infrastructures-visible and invisible-are deeply implicated in individual lives as well as the experience of community, solidarity, and struggles for recognition. Work by Morales, Harris, and Öberg (2014) similarly argues that access to water and sanitation are often key symbolic markers of community enfranchisement and belonging, suggesting that better access or quality of water might be linked to stronger community engagement. Anand's (2011) work in 
Mumbai, India, connects uneven conditions of water access to patterns of engagement- in this example those without adequate access to water are compelled to engage more fully to claim improved access. Kaika's (2005) example above further suggests that those with easy access to high-quality water might be complacent, and therefore less likely to be engaged. This is a situation that likely exists in many industrialized contexts where easy access to affordable water means that people do not have to attend community meetings or interact with government officials to claim basic services (Peloso and Harris 2017; Newell 2005). Other work from behavioral psychology also provides reason to foreground these linkages, notably a recent contribution that finds natural landscape conditions as significant for community attachment (Matarrita-Cascante, Stedman, and Luloff 2010).

Closely connected to our focus, a recent analysis by Bulled (2017) investigates determinants of individual citizen action to improve water services in South Africa. This research considers water insecurity and emotional distress as factors that might influence engagement to improve water access. Findings reported include, among other things, that water insecurity is linked to emotional distress which in turn drives citizen involvement. Apart from these several examples, it is very difficult to find studies that query citizen motivations for engagement as the vast majority of the literature either considers whether participation leads to improved equity or sustainable of resource governance (often there is also the simple and unquestioned assumption that it does) or delves into the sociopolitical implications of shifts toward decentralized and democratic governance (Agrawal 2005; O'Reilly 2010). As such, there remains a significant gap related to the specific factors that might contribute to individual and collective engagement processes.

As a starting point to begin to engage these questions, it is clear that how and whether individuals engage in their communities, or are involved in different aspects of governance, are complicated questions. While we are interested in the linkages between material infrastructural conditions and engagement, we understand that forms of engagement are not likely to be consistent across space, nor for different social groups, but emerge as a complex articulation of political expression, senses of enfranchisement, and structural factors. While there is an expansive literature on participation, including critical approaches that highlight what makes participation inclusive or meaningful (Agrawal and Gibson 1999; Agarwal 2001), our statistical treatment for purposes of this analysis is unable to attend to the quality of the engagement as this would require additional qualitative and ethnographic work. However, we do offer a nuanced analysis, whereby we test the linkages across distinct sites, detail quality, and access as distinct aspects of water materialities, and also speak to variability for population subgroups.

\section{Social Difference, Inequality, and Gender}

Work that speaks to gender, social difference, and inequality in relation to resources is also foundational to our approach. While any statistical analysis should likely consider demographic factors, this is perhaps especially true for work on water ( $\mathrm{Lu}$, OcampoRaederb, and Crow 2014; Sultana 2014). As might be anticipated from the large body of work on gender and water (ibid; Buechler and Hanson 2015), and gender and 
participation (Agarwal 2001; Harris 2009), women are often excluded from governance and may also exhibit strong senses of disenfranchisement. Taking our cue from this research, we included gender, age, and locale in our analysis.

\section{Theoretical Framework and Hypotheses}

Broadly, we ask: how do the material conditions of water, such as access and quality, relate to community engagement? How might these linkages differ for various elements of resource materialities, or for different subsets of the population? Our four testable hypotheses are summarized in Figure 1. For purposes of clarity, we have provided summary names for each: the marginalization hypothesis, enfranchisement hypothesis, necessity hypothesis, and apathy hypothesis. As shown in the figure, hypotheses in opposite corners of the quadrant are correlates.

\section{Marginalization and Enfranchisement Hypotheses (Positive Relationship Between Water Materialities and Engagement)}

Based on the literature reviewed above, we can expect that those who have low-quality water or poor access feel marginalized and do not engage in the community. While we are critical of "hierarchy of needs" debates, those discussions suggest, in line with the "Marginalization hypothesis," that those with poor access or low-quality water may also have low rates of engagement (Scharf, Phillipson, and Smith 2004). One possible reason for this is that one might have to prioritize basic needs, or livelihoods, and would not have time or resources to participate in the community (cf., Mawdesley 2004; Lufumpa 2005). Other scholars have highlighted that poor and inadequate services (and associated senses of indignity) can result in feelings of shame, unworthiness, or embarrassment, all of which can have a dampening effect on engagement (Goldin 2010). Research has suggested that these processes may be more acute for women and other marginalized populations, with women being more sensitive to exclusionary practices, critical thresholds of participation of other women (Agarwal 2010), or emotional-affective dimensions (e.g., feeling valued and that their voices are heard, or shamed for lack of knowledge or illiteracy (Goldin 2010)).

The converse is the "Enfranchisement hypothesis"-someone with good access or good water quality might have strong senses of enfranchisement and "belonging" which in turn can be drivers for engagement (Rosenblatt, Cheshire and Lawrence 2009; Morales 2015). 


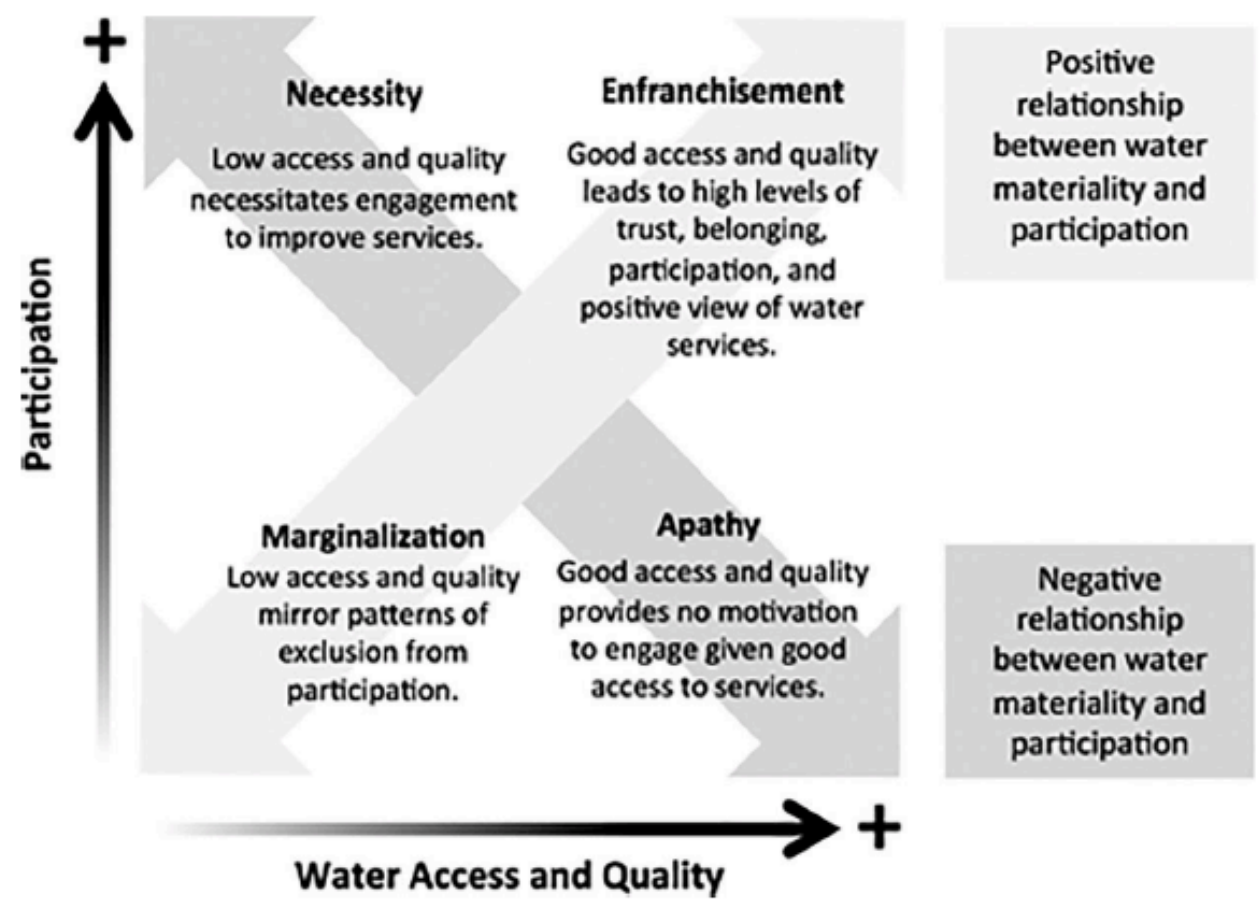

Figure 1. Four hypotheses of the possible relationships between participation and water materialities.

\section{Necessity and Apathy Hypotheses (Negative Relationship Between Materiality and Engagement)}

As several studies have suggested (Hagerty and Williams 1999; Martinez-Alier 2002; Wilkinson and Marmot 2003; Storey 2014), when communities are not satisfied with the access or quality of their water (or other conditions), residents feel motivated to engage in their community-what we term the "Necessity hypothesis." The corollary we termed the "Apathy hypothesis"-if someone's water is easy to access and of high quality, there may be little incentive or interest in to actively engage (recall discussion of Kaika 2005, above). For example, consider how many residents in industrialized contexts must join committees or attend government meetings to secure basic water and sanitation accessan expectation that is often reserved for relatively impoverished communities and lesser developed contexts (Peloso and Harris 2017; Martinez-Alier 2002; Latta and Wittman 2012). In summary, in comparing these hypotheses, the first two would demonstrate a positive relationship between water quality or access and community engagement, while the second set reveals a negative relationship. We ran two-tailed statistical tests to query these relationships.

\section{Data and Methodology}

\section{Study Areas and Data Collection}

Our analysis relies on survey data collected in four sites in two urban contexts (Accra, Ghana and Cape Town, South Africa). The study sites in Ghana and South Africa were chosen primarily due to existing research experience and partnerships, which was crucial for logistics and contextual feedback. Our goal was to select sites in both countries known to 
be facing challenges with water access and quality. For the sites in Ghana water access, quality and affordability are all significant concerns, as residents rely heavily on vendors and generally collect water on a daily pay-per-unit basis. For the South African sites, basic access is fairly secure, with in home taps or communal standpipes serving nearly all homes, mostly free of charge in accordance with the nationally mandated free basic water allocation (Rodina 2016). Yet, the political discourse in South Africa focuses on relative inequality of access within former townships (Tapela 2012) between former townships and other communities (Harris (in process)). concerns related to quality, and problems arising with the shared use of communal taps (with dissatisfaction giving rise to considerable protest in recent years, see Thompson 2011).

As such, while these sites are markedly different, we expected that issues of water access and quality would be pronounced in each, suggesting key similarities. As well, it is clear that water and sanitation conditions are largely determined by forces external to the communities, such as municipal policies, infrastructure investments, and development mandates. Because water materialities in these case studies are not necessarily an outcome of community engagement, this helps to justify our investigation of how material conditions may drive engagement processes, rather than the inverse. ${ }^{1}$ Our focus on community engagement is also particularly apposite given common challenges of engaging marginalized communities more fully in community endeavors as well as senses of citizenship that such engagement might enable (Agarwal 2001; Berry and Mollard 2010; Latta and Wittman 2012).

Data for this article are based on 368 surveys $^{2}$ from the communities of Philippi and Khayelitsha in Cape Town, South Africa and Ashaiman and Teshie in Accra, Ghana. Survey teams were trained in data collection by local collaborators (at the University of Western Cape and the University of Ghana-Legon, respectively). Surveys were conducted in local languages (Xhosa and Afrikaans in Cape Town and Twi and Ga in Accra) and occurred over several weeks, ending in early 2012. Participant selection in both sites was randomized, soliciting participation from every third dwelling unit in Accra and every fourth dwelling unit in Cape Town. ${ }^{3}$

\section{Statistical Analysis}

We used logistic and ordered logistic regression models to examine the probability of community engagement in relation to several factors (Table 1). The following equation is based on the foregoing theoretical discussion. $Y$ is the dependent variable and $X$ is a vector of theoretically important covariates, and $W$ is a vector of control variables.

$$
Y=\operatorname{Logit}(\rho)=\ln \left(\frac{\rho}{1-\rho}\right)=\alpha+\beta_{X} X+\beta_{w} W+\mu_{i}
$$




\section{Variables and Tests}

The dependent variable is "engagement"-a composite variable designed to capture various dimensions of community engagement (see Table 1 for wording of specific questions). It is worth noting that our treatment of "community engagement" is purposefully broad, extending beyond water governance to include involvement in community groups, or consultations with government entities (e.g., participation in District assembly meetings). ${ }^{4}$

Six survey questions were used to measure aspects of "water materialities" (Table 1). A factor analysis of these six questions revealed two primary dimensions: access to water and quality of water (Table 2). The water "quality" variable captures responses to questions as to whether the water is of good quality, if it tastes good, and if it appears clean, and "access" captures responses to ease of getting, access to, and availability of water (see Table 3 for summary statistics of all variables). ${ }^{5}$ We ran a model on the entire data set including data for both Ghana and South Africa to identify any common patterns across the cases, and also ran the models for each country context separately. In addition to the coefficients and odds ratios, we examined predicted probabilities. We calculated average marginal effects ${ }^{6}$ because many of our variables were binary and categorical (and hence a mean estimation of these variables cannot be interpreted). The interaction between gender and age, and the two main materiality factors were included in all models. We also ran tests for "desire to participate," but do not report on those results here due to space constraints and given that the analysis did not differ significantly from that reported here.

Table 1. Model variables.

\begin{tabular}{|c|c|c|c|}
\hline $\begin{array}{l}\text { Variable } \\
\text { types }\end{array}$ & Variables & Questions & Measure \\
\hline $\begin{array}{l}\text { Dependent } \\
\text { Independent }\end{array}$ & Engagement & Multiple questions ${ }^{b}$ & Binary \\
\hline \multirow[t]{5}{*}{ Materiality } & Access to water & It is easy to get water ${ }^{c}$ & $\begin{array}{l}\text { Factor analysis score } \\
\text { (Table 2) }\end{array}$ \\
\hline & & $\begin{array}{l}\text { We face problems with access to regular water }{ }^{c, e} \\
\text { The water is always available }{ }^{c}\end{array}$ & \\
\hline & Water quality & The water we get is of good quality ${ }^{c}$ & \\
\hline & & The water tastes good ${ }^{\mathrm{c}}$ & \\
\hline & & The water looks clean ${ }^{c}$ & \\
\hline \multirow{3}{*}{$\begin{array}{l}\text { Other } \\
\text { variables }\end{array}$} & Worry about water & I worry about a lack of water ${ }^{f}$ & 5-Point scale \\
\hline & $\begin{array}{l}\text { Affordability of water } \\
\text { Gender }\end{array}$ & $\begin{array}{l}\text { For my household, the price of water is affordable }{ }^{c, g} \\
\text { Gender }\end{array}$ & $\begin{array}{l}\text { 4-Point scale } \\
\text { Binary }\end{array}$ \\
\hline & Country & Ghana or South Africa ${ }^{h}$ & Binary \\
\hline \multirow[t]{4}{*}{ Control $^{a}$} & Age & Year of birth & Continuous \\
\hline & Source of water & $\begin{array}{l}\text { From which of the following sources does this } \\
\text { household get its water? }\end{array}$ & Categorical \\
\hline & Employment & $\begin{array}{l}\text { Which of the following employment scenarios } \\
\text { applies to you? }\end{array}$ & Categorical \\
\hline & Trust in Government & To what extent do you trust government officials? ${ }^{k}$ & 5-Point scale \\
\hline
\end{tabular}

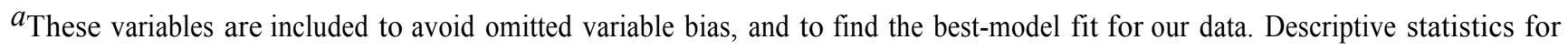
these variables are available on our project website for further information.

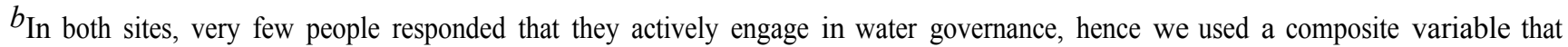
captures diverse forms of community engagement, including participation in government consultation meetings, water entities, or other community groups (such as District Assembly meetings and Community Associations). If a respondent answered yes to
} 
one or more of these modes of participation, we considered them to be "engaged." Use of the index variable allows us to capture diverse forms of engagement in diverse governance and consultation fora.

${ }^{c}$ Respondents were asked if they agreed with the statement on a 5-point Likert scale ranging from "Strongly Disagree" (1) to "Strongly Agree" (5) with a "Neutral" (3) category in the middle.

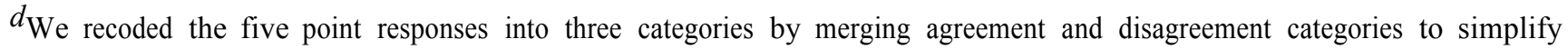
interpretation and graphing of the results.

$e^{e}$ This is coded in reverse order: "strongly disagree" (5), "strongly agree" (1).

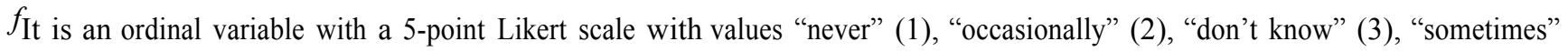
(4), "always" (5).

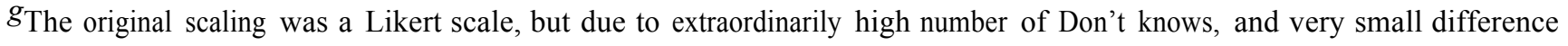
between "strongly (dis)agree" and "(dis)agree" categories, we decided to code it into a four category nominal variable: agree, neutral, disagree, don't know.

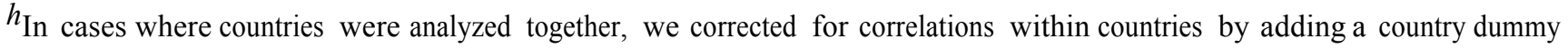
in the models.

${ }^{i}$ Open-ended question coded into a three-category nominal variable: 1) communal source (e.g., communal taps in the South African context), 2) purchased/bottled (including vendor access in Ghana), 3) and in-home or in-yard access.

$j_{\mathrm{A}}$ nominal variable with three categories: 1) employed, 2) under/intermittently employed (including students and selfemployed sellers), and 3) unemployed. In the settlements of Accra we surveyed (Teshie and Ashiaman), many residents are self-employed as street vendors or engage in other forms of informal employment. These respondents were captured in the (under)employment category.

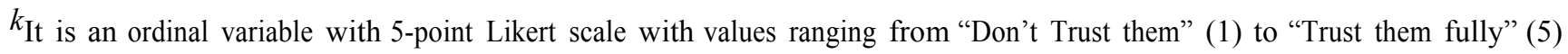
with a middle category of "Don't Know" (3).

Table 2. Factor analysis of water materiality variables.

\begin{tabular}{lccc}
\hline & Factor 1 (water quality) & Factor 2 (water access) & Uniqueness \\
\hline The water we get is of good quality & 0.80 & 0.17 \\
The water tastes good & 0.84 & 0.18 \\
The water looks clean & 0.78 & 0.76 & 0.37 \\
It is easy to get water & & 0.78 & 0.21 \\
The water is always available & & 0.87 & 0.17 \\
We face problems with access to regular water & 3.58 & 3.55 & 0.28 \\
Variance & & & \\
\hline
\end{tabular}

A factor analysis was conducted on eight variables using a principal factor analysis extraction method. The rotation method was promax oblique rotation. Two variables were omitted. "Water smells good" had an overly high uniqueness, and "it is easy to get clean water" was complex and loaded on both factors. The remaining variables loaded on to two main factors: water quality and water access. Blanks represent abs (loading) $<0.3$. 


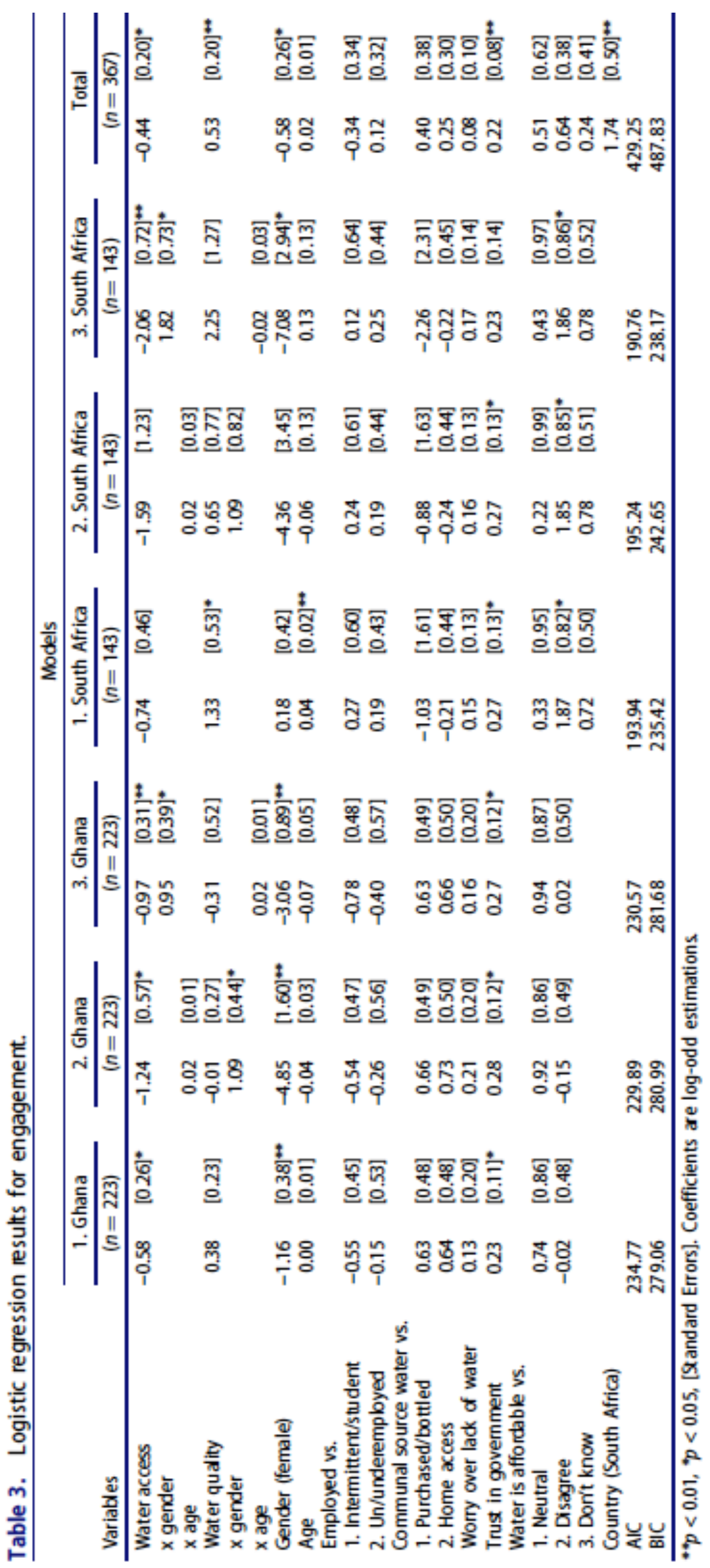




\section{Results}

In terms of general patterns, the minority of survey respondents (35\%) indicated that they are engaged in the community. Ghana had considerably lower engagement (21\%) than South Africa (48\%). Overall for the combined data set, women and men's engagement was similar (34 and 36\%, respectively), but Ghanaian women had the lowest levels of community engagement (12\%), while South African women were the highest (52\%). There was considerable variation across countries, e.g., in Ghana $30 \%$ of men were engaged compared with $42 \%$ of men in South Africa.

The model that included data from both countries revealed that water access and quality were both significant predictors of engagement; however, they exhibit opposite relationships (Table 3): while water quality is positively associated with engagement, water access reveals a negative relationship. In terms of probabilities, we find that as water quality increased from minimum to maximum (zero to five in our measures), the predicted probability of engagement increased by almost 40\% (see Appendix, Table 4). However, as water access increased from its minimum to maximum value (zero to five in our measures), the predicted probability of engagement decreased by $45 \%$ (see Appendix Table 4). In the following sections, we examine these linkages in greater detail.

\section{Relationship Between Water Access and Engagement}

As noted, from our combined data set (both countries), we find that access to water and engagement are negatively related. When the countries are examined separately, the negative trend is consistent for both countries, but is only statistically significant in Ghana (Table 3). Our analysis also shows that the effect of water access is conditional on gender; interaction terms are significant in both Ghana and South Africa (Table 3). The results suggest that the probability of women's engagement is comparatively steady regardless of access to water, whereas the probability of men's engagement decreases with improved water access (Figure 2). Hence, men in the sample are sensitive to access as a driver of their engagement (with engagement diminishing as access improves) and drove the overall negative effect, while female respondents (in both countries) were engaged in the same proportion regardless of access (Figure 2). Taken together, for water access, we find support for the linked "apathy" and "necessity" hypotheses, meaning that those who are well served in terms of water access are less likely to engage in the community, and those who are poorly served in terms of access are more likely to be engaged. Here, the important caveat is that it is male respondents driving this trend. There is no significant interaction between engagement and water access with age.

\section{Relationship Between Water Quality and Community Engagement}

When examining both countries together, the relationship between quality of water and engagement is significant and positive (the opposite relationship as that found for access; Table 3). When the countries are examined separately, the positive trend is the same in both countries, but it is only statistically significant in South Africa (Table 3). 

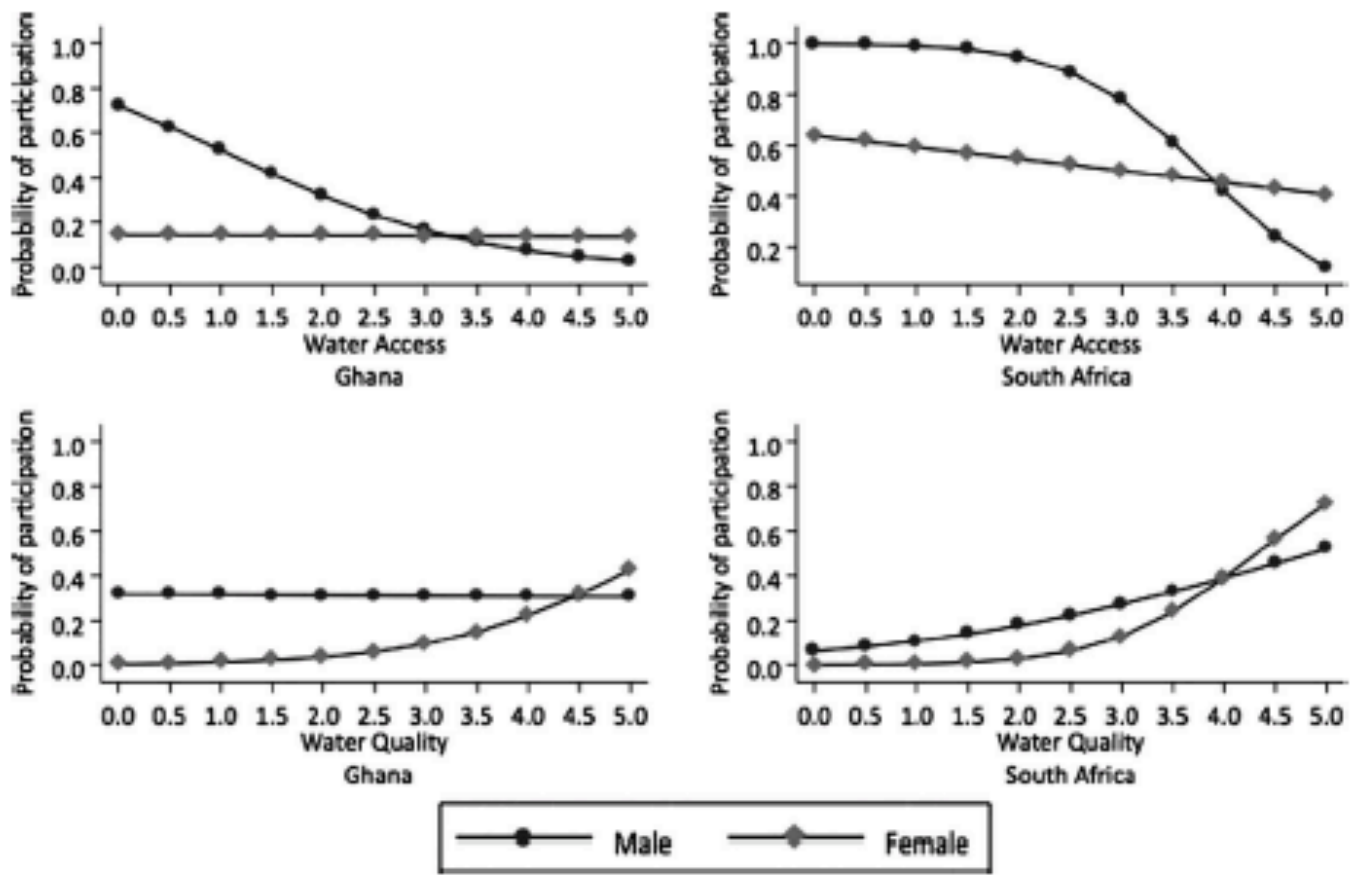

Figure 2. Average predicted probabilitles of particlpation (y-axis) is calculated for water access ( $x$-ax|s), and water quality over gender when holding other varlables at thelr original values. Countrles are plotted separately.

Examining the countries separately and including the interaction of gender, a more nuanced pattern emerges. In South Africa, there is no significant difference between men and women with respect to the positive effect of water quality on probability of engagement; but in Ghana only women's probability of engagement increases with water quality, while men's probability of engagement remains relatively stable (Table 3; Figure 2). Here, using the language of sensitivity, it appears that engagement increases for both men and women in South Africa as quality improves. Yet, for Ghana, women were sensitive to water quality as a driver of engagement, while men were not (thus explaining why the effect of water quality does not emerge as significant in Ghana, as male respondents effectively dampened the trend). To speak back to our hypotheses, overall, we observe a pattern whereby engagement increases as the quality of the water improves in support of the coupled "marginalization" and "enfranchisement" hypotheses (Figure 1), with some differences in terms of only women being sensitive to quality in Ghana. There is no significant interaction with age.

As detailed in Table 3, but not highlighted in the discussion, several other variables were also significant in the models: in South Africa, affordability of water negatively relates to engagement. Trust in government is significant in all the models run above (for both countries) and it is positively correlated with engagement.

\section{Discussion}

Overall, we find that water access and quality are significant drivers of community engagement. We find that the relative effect of these variables is conditional on the country 
setting as well as demographic variables, notably gender. Most interestingly, we find that access and quality work in opposite directions (negative and positive, respectively, and as such, support different hypotheses). Also notable, women appear to be more driven to engage in community action by quality and men by access. An overarching insight is that it is not possible to make generalized predictions about how water access or quality may impinge on community engagement-rather these linkages are dependent on the specific relationships of these populations to water. As such, this finding echoes a long-standing theme in the literature related to different populations' specific knowledge or use of resources (Rocheleau, Thomas-Slayter, and Wangari 1996; Buechler and Hanson 2015). Speaking back to materiality debates, we also offer the insight that various aspects of materiality need to be considered separately. We provide further discussion and contextualization of the results below.

\section{Facets of Water Materialities}

Given that "access" and "quality" are significant predictors of engagement, our results augment suggestions in the literature that we need to take materialities seriously (e.g., Bakker and Bridge 2006). However, given that these factors affect engagement differently, it is clear that specific aspects of materialities need to be treated as distinct in terms of how they might impinge on social, political, and institutional processes.

\section{Water Access}

Overall, water access is a primary factor driving community engagement-with lower access correlated with higher probabilities of engagement and better access to water being correlated with lower probabilities of community engagement. This pattern was driven by male respondents-women's participation was not as sensitive to access. Relating to our original hypotheses, for men specifically, if access to services is sufficient, there may be fewer incentives for community members to engage (necessity-apathy hypothesis).

The fact that this pattern does not hold for women suggests that women (especially in South Africa) are engaged in the community irrespective of their water access. Further possible interpretations of this gender divide are provided below.

\section{Water Quality}

Regarding water quality, the overall relationship is positive (better quality water is linked to stronger engagement), and is an effect that is driven by female respondents. In other words, access and quality with respect to gendered patterns of engagement are mirror images of each other.

\section{Gender, Age, and Other Factors}

In relation to the larger body of work on gender, inequality, and water, our results can be read as supportive of several familiar claims. For instance, the broader literature suggests that women may be more concerned with water quality than men (given women's labor and household responsibilities, related to cooking, well-being or care for ill household members, e.g., Harris 2009; O'Reilly 2010). Here it is possible that men are more attentive

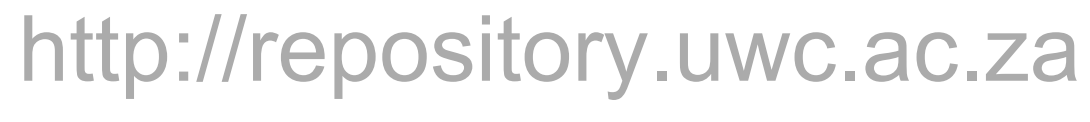


to access (e.g., whether there is water available for bathing and other basic household uses), while women may be more sensitive to the actual quality of that water (e.g., whether it is suitable for drinking, cooking, and other domestic uses).

The fact that male respondents align with the apathy-necessity hypothesis and women more with the marginalization-enfranchisement hypothesis is also interesting with respect to the broader literature on gender and participation. For instance, to the degree that women are marginalized, women might be more sensitive in responding to positive cues of enfranchisement (Goldin 2010). For instance, women might put particular weight on high quality of water as a key indicator of belonging, spurring further engagement in their community (Morales and Harris 2014). Meanwhile, men might only engage in their community to the extent that they have to in order to secure basic access, and will opt out if their needs are being served (necessity-apathy hypothesis).

While the gender analysis adds considerable complexity to our results, we also consider that this dimension of the work serves as strong affirmation of the importance of collecting data and undertaking analyses attentive to these differences. In brief, the importance of gender was undeniable in our results. By taking this approach, we are able to offer statistical validation to themes that are present in the broader literature, but that are often based on a single context or on qualitative methods drawing on a very small subset of interviews (Harris, Kleiber, Goldin, Darkwah, and Morinville 2016).

\section{Geographic Context}

Country differences were clearly decipherable in our results. For instance, access was statistically significant for the combined data set and in the Ghana model, but not when we isolate South Africa, where we observe more pronounced patterns linked with water quality. This result makes sense given our appreciation of the daily water concerns in the sites where the survey was undertaken. To recall, basic access in South Africa is relatively secure, while fewer than half our Ghanaian respondents have regular secure access. The relative focus on access in Ghana and quality in South Africa is thus understandable.

Further, it is notable that quality was a key concern in South Africa and was linked positively with engagement. Given politics of racialized marginalization and exclusion in South Africa (Goldin 2010; Thompson 2011), it is possible that the marginalizationenfranchisement-hypotheses are particularly relevant in this context where tremendous weight is put on equal access to high-quality services (and not merely basic access) as a powerful marker of full citizenship and belonging to community (Mahlanza, Ziervogel, and Scott 2016; Rodina and Harris 2016). On the other hand, for Ghana, where access is insecure, impoverishment is widespread, and affordability concerns are common (a considerable portion of the population in Accra pays as much as a quarter of their income on basic water access), it is perhaps understandable that the necessity-apathy hypothesis holds greater salience (Amenga-Etego and Grusky 2005; Oteng-Ababio, Smout, and Yankson 2017) 


\section{Revisiting Key Hypotheses}

In sum, returning to our hypotheses, we find support for both the marginalizationenfranchisement (especially for women, for water quality, and in South Africa) and apathy-necessity hypotheses (especially for men, for water access, and in Ghana). This leaves some unanswered questions meriting further mixed methods research. For instance, it is worth further study to understand the sensitivity of different populations to different aspects of materialities, or to consider critical thresholds or sequencing that might be at play with regard to differences between quality and access concerns.

\section{Conclusion}

To conclude, we offer several insights and ways forward.

First, the results validate the importance of resource materialities in conditioning sociopolitical and institutional dynamics. To our knowledge, no other study has specifically tested the relationship between specific resource conditions and community engagement. Offering statistical validation for the types of linkages often theorized in growing bodies of work on political ecologies and anthropologies of infrastructure (von Schnitzler 2008; Morales 2015), we are poised to better address the role of water infrastructures in social lives toward the goal of better resource management and policy (Krause and Strang 2016).

Second, we provide a quadrangle of hypotheses (Figure 1) related to water materialities and community engagement. This framework provides a robust tool to inform our analysis as well as further research on connections between resource conditions, infrastructures, sociopolitical dynamics. These relationships have been implied in the literature, but are rarely explicit, nor elaborated in terms of hypotheses that can be analyzed and tested.

Third, speaking to conceptual debates on resource materialities, we highlight the need to disaggregate different material conditions. Here, factor analysis showed that access and quality are two key elements that are both significant, yet are linked with engagement in opposite directions. While materialities have often been taken as the biophysical characteristics or physical properties of the object of focus (i.e., the resource), our results suggest the need for nuance and careful thinking about the specific conditions of resources, and how they may variously condition sociopolitical dynamics.

Fourth, by quantitatively testing these relationships, we are also able to validate broader themes from the literature related to sociopolitical difference and inequality, notably gender as important for the intersection of water access, quality as well as for community engagement (cf., Wutich et al. 2013). Despite limitations that come with our methods (as with any method), quantitative analysis is useful to substantiate and specify relationships and pathways. In terms of methodological contributions, our results also highlight the importance of disaggregated analysis by country as well as interactions with gender and other axes of social difference, as some of the nuances only became visible in relation to 
these complexities. We thus endorse suggestions made in the literature that data collection and study design should enable disaggregated analyses (Kleiber, Harris, and Vincent 2014; Seager 2010).

Fifth, our approach helped reveal several context-specific and policy-relevant insights. For South Africa, while access to water is nearly universal, significant concerns remain related to the quality of water and sanitation services as well as senses of relative inequality (Mahlanza, Ziervogel, and Scott 2016; Rodina 2016), all of which are important for community engagement and senses of enfranchisement. As our results show, engagement improves for both men and women in South Africa as water quality improves, suggesting potential policy pathways for improving participation and governance. Indeed, our ongoing qualitative work in these contexts reveals that water and sanitation remain important markers of inclusion in the promise of an equitable and democratic South Africa Haris (in process) while other ongoing work similarly shows that failures to meet service expectations are likely to result in ongoing protest and contestation (Thompson 2011). For Ghana, policies informed by these results might do well to continue to make progress on basic access as a key concern. That said, given the particularly low rates of community engagement among women in Ghana, other efforts should also be geared toward building senses of enfranchisement and increasing community engagement over the long term.

Sixth, and finally, our analysis leaves us with further questions. Among the questions we find most compelling for further research is how and why men and women, and within our two country contexts, align differently with respect to the varied hypotheses. Among the interesting possibilities emerging from the analysis, there is the suggestion that women might be more sensitive to cues of community enfranchisement, responding positively to water quality as a potential marker of belonging. We are also curious as to whether or not for other community engagement processes (and in other contexts), men would similarly opt out if they feel their needs are being served (e.g., in line with the necessityapathy hypothesis)? These possibilities merit further evaluation. We propose that mixed methods approaches undertaken in diverse contexts would be useful to further disentangle some of these linkages. Doing so is likely to reveal a great deal for engagement challenges as well as for resource use, conditions, and governance more generally. 


\section{Notes}

1. To clarify potential issues of endogeneity, we looked to see if our dependent variable is endogenous to our independent variables. We used instrumental variables (availability permitting) and ran a probit model with continuous endogenous regressors. We then conducted Wald tests of exogeneity for the variables (water access and quality). We are able to show that the variables are exogenous. Details on these tests are available on the project website, www.www.www.

2. Surveys with missing data were omitted from analysis to ensure that the same observations were useed across different models for consistency, resulting in 224 surveys from Ghana and 144 from South Africa.

3. While space limitations do not allow us to go into considerable detail related to these sites, more information is available on the project website www.tobeaddedafterreview.com.

4. We acknowledge that protest and other forms of engagement might also be important (Thompson 2011), albeit difficult to capture due to political sensitivities. Participation in church and sports was excluded from the analysis since rates of engagement in these domains was nearly universal.

5. While we are aware of the important and complex discussion of what constitutes access or quality (cf., Mahama, Anaman, and Osei-Akoto 2014), here we draw on survey responses to several questions and bundle these to operationalize "access" and "quality" for the analysis, relying on respondents' own sense of these rather than attempting to independently validate those variables (Table 1 ).

6. Average marginal effects were calculated using the Stata "margins" command.

\section{Acknowledgments}

We are deeply grateful for the support and cooperation of the Anthropology of Water Research Group, University of the Western Cape; EDGES @ UBC (Environment and Development: Gender, Equity, and Sustainability Perspectives Research Collaborative, University of British Columbia) as

Equity, and Sustainability Perspectives Research Collaborative, University o well as Akosua Darkwah and colleagues at the University of Ghana-Legon.

\section{Funding}

The Center for International Governance Innovation, Peter Wall Institute for Advanced Studies, University of British Columbia, The Stellenbosch Institute for Advanced Study, and Social Sciences and Humanities Research Council of Canada all provided funding support for this research. 


\section{References}

Agarwal, B. 2001. Participatory exclusions, community forestry, and gender: An analysis for South Asia and a conceptual framework. World Development 29 (10):1623-48. doi:10.1016/s0305-750x (01)00066-3

Agarwal, B. 2010. Does women's proportional strength affect their participation? Governing local forests in South Asia. World Development 38 (1):98-112. doi:10.1016/j.worlddev.2009.04.001

Agrawal, A. 2005. Environmentality: Technologies of government and the making of subjects. Durham, NC: Duke University Press.

Agrawal, A., and C. Gibson. 1999. Enchantment and disenchantment: The role of community in natural resource conservation. World Development 27 (4):629-49. doi:10.1016/so305-750x(98)oo161-2

Amenga-Etego, R. N., and S. Grusky. 2005. The new face of conditionalities: The World Bank and water privatization in Ghana. In The age of commodity: Water privatization in Southern Africa, ed. D. A. McDonald and G. Ruiters, 275-90. London and Sterling, VA: Earthscan.

Amin, A. 2014. Lively infrastructure. Theory, Culture and Society 31 (7/8):137-61. doi:10.1177/0263276414548490

Anand, N. 2011. Pressure: The poliTechnics of water supply in Mumbai. Cultural Anthropology 26 (4):542-64. doi:10.1111/j.1548-1360.2011.01111.x

Barnes, J., and S. Alatout. 2012. Water worlds. Special Issue Social Studies of Science 42 (4):483-88. doi:10.1177/0306312712448524

Bakker, K. 2003. An uncooperative commodity: privatizing water in England and Wales. Oxford, UK: Oxford University Press.

Bakker, K., and G. Bridge. 2006. Material worlds? Resource geographies and the 'matter of nature'. Progress in Human Geography 30 (1):5-27. doi:10.1191/0309132506ph5880a

Berry, K., and E. Mollard. 2010. Social participation in water governance and management: critical and global perspectives. London, Sterling, VA: Earthscan.

Birkenholtz, T. 2009. Irrigated Landscapes, Produced Scarcity, and Adaptive Social Institutions in Rajasthan, India. Annals of the Association of American Geographers 99 (1):118-137.

Buechler, S., and A. S. Hanson. 2015. A political ecology of women, water, and global environmental change. New York, NY: Routledge.

Bulled, N. 2017. The effects of water insecurity and emotional distress on civic action for improved water infrastructure in Rural South Africa. Medical Anthropology Quarterly 31 (1):133-54. doi:10.1111/maq.12270

Goldin, J. A. 2010. Water Policy in South Africa: Trust and Knowledge as Obstacles to Reform. Review of Radical Political Economics 42 (2):195-212.

Hagerty, B. M., and A. Williams. 1999. The effects of sense of belonging, social support, conflict, and loneliness on depression. Nursing Research 48 (4):215-19. doi:10.1097/00006199-199907000-00004

Harris, L. (in process). Assessing States and Evaluating Publics: Perspectives on water sector service delivery and citizen responsibility in Accra, Ghana and Cape Town, 
South Africa.

Harris, L. 2009. Gender and Emergent Water Governance: Comparative Overview of Neoliberalized Natures and Gender Dimensions of Privatization, Devolution, and Marketization. Gender, Place and Culture 16 (4):387-408.

Harris, L. M., Kleiber, D., Goldin, J., Darkwah, A., and C. Morinville. 2016. Intersections of Gender and Water: Comparative approaches to everyday gendered negotiations of water access in under-served areas of Accra, Ghana and Cape Town, South Africa. Journal of Gender Studies doi:10.1080/served areas of Accra, G 09589236.2016.1150819

Kaika, M. 2005. City of Flows: Nature, modernity and the city. London, UK: Routledge.

Kleiber, D., Harris, L. M., and A. Vincent. 2014. Gender and small-scale fisheries: a case for counting women and beyond. Fish and Fisheries, Feb 2014 Early View.

Kooy, M., and K. Bakker. 2008. Technologies of government: Constituting subjectivities, spaces, and infrastructures in colonial and contemporary Jakarta. International Journal of Urban and Regional Research 32 (2):375-91. doi:10.1111/j.14682427.2008.00791.x

Krause, F., and V. Strang. 2016. Thinking relationships through water. Society \& Natural Resources 29 (6):633-38. doi:10.1080/08941920.2016.1151714

Larkin, B. 2013. The politics and poetics of infrastructure. Annual Review of Anthropology 42:327-43. doi:10.1146/annurev-anthro-092412-155522

Latta, A., and H. Wittman. 2012. Environment and citizenship in Latin America: Natures, subjects, and struggles. New York, NY: Berghahn Books.

Linton, J. 2012. The human right to what? Water, rights, humans and relation of things. In The right to water: Politics, governance, and social struggles, ed. F. Sultana and A. Loftus, 45-61. London: Earthscan.

Lu, F., C. Ocampo-Raederb, and B. Crow. 2014. Equitable water governance: future directions in the understanding and analysis of water inequities in the global South. Water International 39 (2):129-42. doi:10.1080/02508060.2014.896540

Lufumpa, C. L. 2005. The poverty-environment nexus in Africa. African Development Review 17 (3):366-81. doi:10.1111/j.1017-6772.2006.00120.x

Mahama, A. M., K. A. Anaman, and I. Osei-Akoto. 2014. Factors influencing householders' access to improved water in low-income urban areas of Accra, Ghana. Journal of Water and Health 12: 318-31. doi:10.2166/wh.2014.149

Mahlanza, L., G. Ziervogel, and D. Scott. 2016. Water, rights and poverty: An environmental justice approach to analysing water management devices in Cape Town. Urban Forum 27:363-82. doi:10.1007/s12132-016-9296-6.

Matarrita-Cascante, D., R. Stedman, and A. E. Luloff. 2010. Permanent and seasonal residents' community attachment in natural amenity-rich areas: Exploring the contribution of landscape-related factors. Environment and Behavior 42 (2):197-20. doi:10.1177/0013916509332383

Martinez-Alier, J. 2002. Environmentalism of the poor: A study of ecological conflicts and valuation. Cheltenham, UK, Edward Elgar.

Mawdesley, E. 2004. India's middle class and the environment. Development and Change 35 (1): 79-103. 
Morales, M. 2015. My pipes say I am powerful: Belonging and class as constructed through our sewers. Wires Water 3 (1):63-73 doi:10.1002/wat2.1108

Morales, M. and L. Harris. 2014. Using Subjectivity and Emotion to Reconsider Participatory Natural Resource Management. World Development 64:703-712

Morales, M., L. Harris, and G. Öberg. 2014. Citizenshit: The right to flush and the urban sanitation imaginary. Environment and Planning $A \quad 46$ (12):2816-33. doi:10.1068/a130331p

Newell, P. 2005. Race, class and the global politics of environmental inequality. Global Environmental Politics 5 (3):70-94. doi:10.1162/1526380054794835

O'Reilly, K. 2010. Combining sanitation and women's participation in water supply: An example from Rajasthan. Development in Practice 20 (1):45-56.

Oteng-Ababio, M., I. K. Smout, and P. W. K. Yankson. 2017. Poverty politics and governance of

potable water services: The core-periphery syntax in Metropolitan Accra, Ghana. Urban Forum 28:185-203. doi:10.1007/s12132-017-9301-8

Peloso, M., and L. Harris. 2017. Forthcoming Pathways for participatory water governance in Ashaiman, Ghana: Learning from Institutional Bricolage and Hydrosocial perspectives. Society and Natural Resources.

Pretty, J., and H. Ward. 2001. Social capital and the environment. World Development 29 (2):209-27. doi:10.1016/s0305-750x(00)00098-x

Putnam, R. 1993. Making democracy work: Civic traditions in modern Italy. Princeton, NJ: Princeton University Press.

Rocheleau, D., B. Thomas-Slayter, and E. Wangari. 1996. Feminist political ecology: Global issues and local experiences. New York, NY: Routledge

Rodina, L. 2016. Human right to water in Khayelitsha, South Africa - Lessons from a 'lived experiences' perspective. Geoforum 72:58-66. doi:10.1016/j.geoforum.2016.04.003

Rodina, L., and L. Harris. 2016. Water Services, Lived Citizenship, and Notions of the State in Marginalised Urban Spaces: The case of Khayelitsha, South Africa. Water Alternatives 9 (2):336-355.

Rosenblatt, T., L. Cheshire, and G. Lawrence. 2009. Social interaction and sense of community in a master planned community. Housing, Theory and Society 26 (2), 122-42. doi:10.1080/14036090701862484

Scharf, T., C. Phillipson, and A. E. Smith. 2004. Poverty and social exclusion-growing older in deprived urban neighbourhoods. In Growing older: Quality of life in old age, ed. A. Walker and C. Hagan Hennessy, 81-106. Maidenhead, UK: Open University Press.

Seager, J. 2010. Editorial: Gender and water: Good rhetoric, but it doesn't count. Geoforum 41:1-3.

Storey, A. 2014. Making experience legible: Spaces of participation and the construction of knowledge in Khayelitsha. Politikon 41 (3):403-20. doi:10.1080/02589346.2014.975935

Sultana, F. 2009. Community and participation in water resources management: gendering and naturing development debates from Bangladesh. Transactions of the Institute for British Geographers 34:346-63. doi:10.1111/j.1475- 
5661.2009.00345.x

Sultana, F. 2014. Gendering climate change: Geographical insights. The Geographical Journal 66 (3):372-81. doi:10.1080/00330124.2013.821730

Sultana, F., and A. Loftus. 2012. The right to water: Politics, governance, and social struggles. London: Earthscan.

Tapela, B. N. 2012. Social water scarcity and water use (No. 1940/1/11) 175. Cape Town, South Africa: Water Research Commission.

Thompson, L. 2011. Forms of citizen participation in local governance and links to service delivery protests. Africanus 41 (1):1-2.

von Schnitzler, A. 2008. Citizenship prepaid: Water, calculability, and techno-politics in South Africa. Journal of Southern African Studies 34 (4):899-17. doi:10.1080/03057070802456821

Wilkinson, R. G., and M. Marmot. 2003. Social determinants of health: The solid facts. Copenhagen, Denmark: World Health Organization.

Wutich, A., A. Brewis, S. Sigurdsson, R. Stotts, and A. M. York. 2013. Fairness and the human right to water: A preliminary cross-cultural theory. In The social life of water, ed. J. R. Wagner, 220-38. New York, NY: Berghahn Books.

\section{Appendix}

Table 4. Predicted Probabilitles of Engagement by Water Access.

\begin{tabular}{|c|c|c|c|c|c|c|c|}
\hline \multicolumn{2}{|c|}{ Measure of Materlality } & \multirow{2}{*}{$\begin{array}{c}\begin{array}{c}\text { Probability of } \\
\text { Particlpation }\end{array} \\
0.58\end{array}$} & \multirow{2}{*}{$\frac{\text { Std. Err. }}{0.14}$} & \multirow{2}{*}{$\frac{z}{4.23}$} & \multirow{2}{*}{$\frac{P>|z|}{0.00}$} & \multicolumn{2}{|c|}{$\begin{array}{l}95 \% \text { Conf. } \\
\text { Interval }\end{array}$} \\
\hline A. Water Access & 0 & & & & & 0.31 & 0.84 \\
\hline & 1 & 0.47 & 0.09 & 5.08 & 0.00 & 0.29 & 0.64 \\
\hline & 2 & 0.36 & 0.05 & 7.96 & 0.00 & 0.27 & 0.45 \\
\hline & 3 & 0.26 & 0.03 & 9.99 & 0.00 & 0.21 & 0.32 \\
\hline & 4 & 0.19 & 0.04 & 4.47 & 0.00 & 0.11 & 0.27 \\
\hline & 5 & 0.13 & 0.05 & 2.51 & 0.01 & 0.03 & 0.23 \\
\hline \multirow[t]{6}{*}{ B. Water Quality } & 0 & 0.05 & 0.04 & 1.41 & 0.16 & -0.02 & 0.12 \\
\hline & 1 & 0.09 & 0.04 & 1.97 & 0.05 & 0.00 & 0.17 \\
\hline & 2 & 0.14 & 0.04 & 3.16 & 0.00 & 0.05 & 0.22 \\
\hline & 3 & 0.21 & 0.03 & 6.53 & 0.00 & 0.15 & 0.28 \\
\hline & 4 & 0.32 & 0.03 & 10.75 & 0.00 & 0.26 & 0.37 \\
\hline & 5 & 0.44 & 0.07 & 6.50 & 0.00 & 0.31 & 0.57 \\
\hline
\end{tabular}

Average predicted probabilitles of engagement are calculated for water access and quality when holding other varlables at their original values. 